\title{
Introduction - Developmental Overview of the Human Embryo
}

\author{
Shigehito Yamada ${ }^{1}$, and Tetsuya Takakuwa ${ }^{2}$ \\ ${ }^{1}$ Congenital Anomaly Research Center, Kyoto University, \\ ${ }^{2}$ Human Health Science, Kyoto University, \\ Japan
}

\section{Introduction}

In this chapter, we provide a historical background on human embryo collections and describe their significant contribution to the understanding of human ontogenesis. More particularly, an overview of human embryonic development is presented using computergenerated images obtained from embryonic specimens housed at the Kyoto Collection in Japan.

\subsection{Human embryology and embryo collections}

Historically, several human embryo collections have been created. The Carnegie Collection, the Blechschmidt Collection, the Hinrichsen Collection and the Kyoto Collection are reported as the four famous compendiums of human embryos in the world. The Carnegie Collection is the oldest and was established as early as 1887, while the Blechschmidt collection was created in 1948 by the Göttingen anatomist Erich Blechschmidt, well known for its contribution to the development of novel methods of reconstruction. In 1961, the Kyoto Collection of Human Embryos was instigated, followed by the Hinrichsen Collection in 1969. While the Blechschmidt and the Hinrichsen collections are described in Chapter 2, here, we focus on the Carnegie and the Kyoto Collections.

\subsection{The carnegie human embryo collection}

The basis of the Carnegie Human Embryo Collection was established by Franklin P. Mall. After earning his medical degree at the University of Michigan in 1883, Mall traveled to Germany to receive a clinical training and there he met Wilhelm His and other eminent biologists. Mall then became aware of the importance of studying human embryology, and initiated a collection of human embryos in 1887. When he returned to the United States and took on a position in the Anatomy department of the Johns Hopkins School of Medicine in Baltimore, Maryland, he already had in his possession several hundreds of specimens. In 1913, as a professor of Anatomy at the Johns Hopkins School of Medicine, Mall applied for a Carnegie grant to support his research on human embryos, was successful in his application and thus, in 1914, became the first director of the Department of Embryology at the Carnegie Institution of Washington, in Baltimore, MD. The collection grew up at a rate of about 400 
specimens a year, and the number of samples attained over 8,000 by the early 1940 s. The most difficult task, however, was to organize and catalogue the collection. Age or size proved to be a poor way to organize embryos, as embryos could shrink a full $50 \%$ in the preserving fluids. Mall devised a better way and based his staging scheme on morphological characteristics instead. To that end, Mall and his colleagues not only prepared and preserved serial sections of the embryos; they also made hundreds of three-dimensional models at different stages of growth. Over 700 wax-based reconstructions were created.

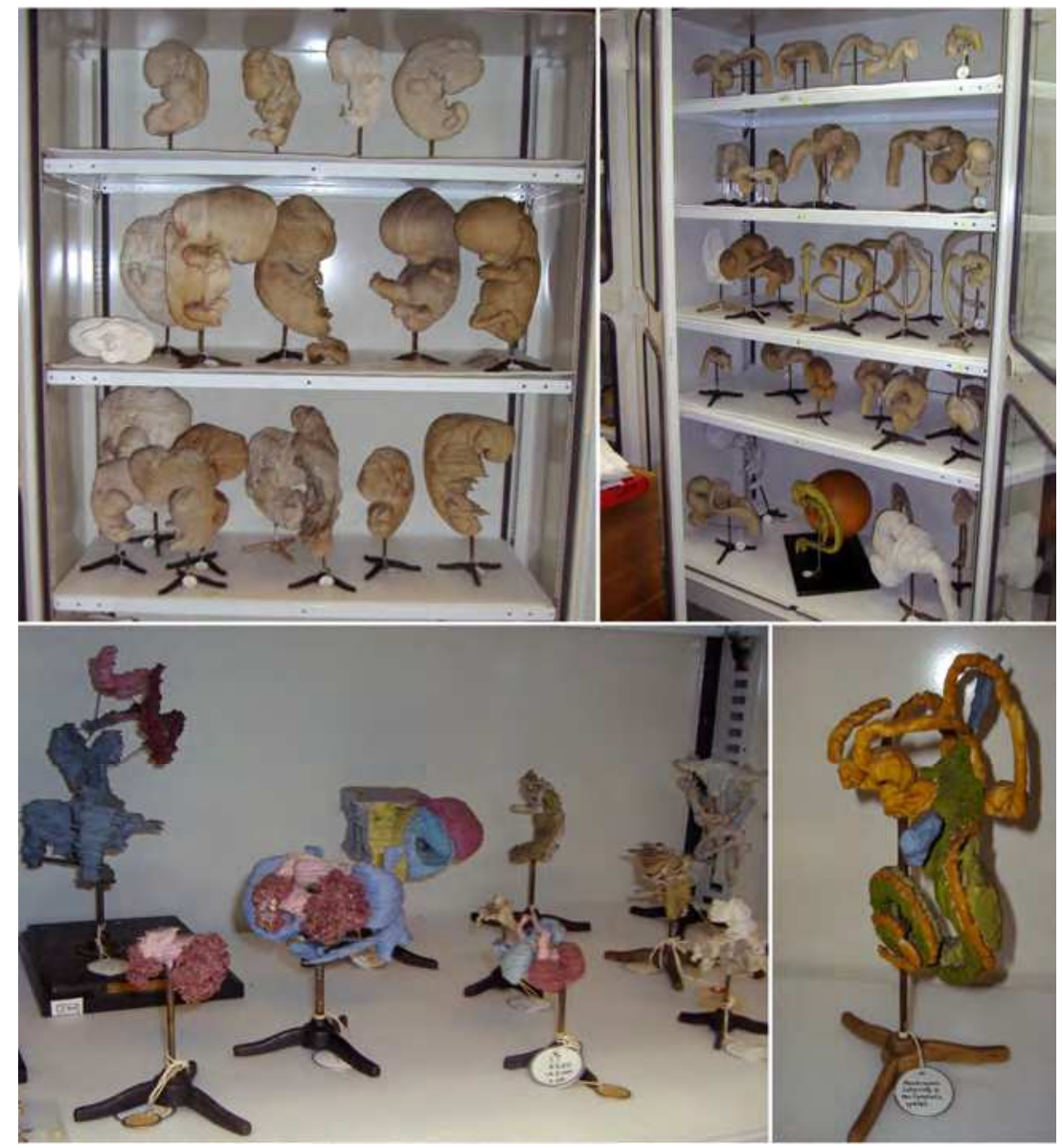

Fig. 1. Wax reconstruction models at the Carnegie Collection, housed at the National Museum of Health and Medicine, Washington, DC. Surface reconstruction of human whole embryos (top left), neural tubes and brains (top right), hearts and great vessels (bottom left), and membranous labyrinth and perilymphatic spaces (bottom right).

Throughout the Mall's era, several members of his department became renowned scientists. George L. Streeter and Franz J. Keibel were both former students of Wilhelm His; Osborne O. Heard worked as an embryo modeler; and James D. Didusch as a scientific 
illustrator. Mall documented his research in a series of papers compiled in the Contributions to Embryology of the Carnegie Institution of Washington, published from 1915 to 1966. Today, these articles are still regarded as textual and visual standards for human embryologists. In 1917, Mall unexpectedly died, and Streeter became the second director of the Department of Embryology. Under his supervision, hundreds of specimens continued to join the collection every year. Notable were the rare, very young normal specimens. At the time, induced abortions were illegal in the United States and miscarriages usually result in abnormal embryos. Streeter was the first to define the 23 Carnegie Stages currently used to classify the developmental stages of the human embryo.

When Streeter retired in 1940, George W. Corner became the third director of the department. Corner was a former Johns Hopkins researcher who discovered the ovarian hormone progesterone. Under his direction, many advances in human reproductive physiology were made. Research in human embryology continued to be actively pursued, but came to an end in 1956 with the succeeding director. In 1973, the Collection was sent to the University of California at Davis Medical School, where the Carnegie Laboratories of Embryology, under the directorship of Ronan O'Rahilly, officially opened in 1976. In 1991, following O'Rahilly's retirement, the collection was donated to the National Museum of Health and Medicine, located at the Walter Reed Army Medical Center in Washington, D.C. The specimens remain available for use by researchers, and are in high demand. Adrianne Noe and colleagues have generated an online database system for easy information access to some 660 embryos from the collection. These embryos were selected to represent the full range of embryonic growth from single cells through to eight weeks of age. The Carnegie Collection forms the centerpiece of the Human Developmental Anatomy Center, and is used by hundreds of researchers every year. Further details of the embryo collection can be found in earlier publications (Brown, 1987, O'Rahilly, 1988) as well as on the web (http://nmhm.washingtondc.museum/ collections/hdac/carnegie_history.htm).

\subsection{The Kyoto collection of human embryos}

In 1961, Hideo Nishimura, Professor in the Department of Anatomy at Kyoto University School of Medicine, instigated a collection of human conceptuses. Induced abortions were then legal in Japan under the Maternity Protection Law of Japan, therefore, in a great majority of cases; pregnancies were terminated for social reasons during the first trimester. Fifteen years later, the number of specimens reached over 36,000 and the Congenital Anomaly Research Center was created in 1975. Today, the embryo collection comprises over 45,000 specimens, and represents the largest human embryo collection in the world. The specimens were primarily obtained from pregnancies interrupted by dilatation or curettage. Other specimens resulted from spontaneous or threatened abortions. When the aborted materials were brought to our laboratory, the embryos were measured, staged, and examined for gross external abnormalities and signs of intrauterine death under a dissecting microscope. The developmental stage of the embryos (Carnegie stage: CS) was determined according to the criteria proposed by O'Rahilly and Müller (1987). Since the attending obstetricians were not involved in examining the aborted materials, the collection of embryos was not biased by their outcome (e.g., normal or abnormal, live or dead), thus, the embryo collection is considered representative of the total intrauterine population in Japan (Nishimura, 1974, 1975). Using this representative embryo population, it was reported that 
the incidence of malformations in embryos were more frequent than that in infants (Nishimura et al., 1968), and that embryos with severe malformations were prone to spontaneous abortion at high rates (Shiota, 1991). Of these embryonic malformations, holoprosencephaly (HPE) was observed at a high frequency in the Kyoto Collection. HPE is a group of malformation characterized by specific dysmorphia of the brain and the face. They are caused by an impaired or incomplete midline cleavage of the prosencephalon into cerebral hemispheres. Although HPE is a rather rare anomaly in newborns $(1 / 10,000$ $20,000)$, it is encountered much more frequently (1/250 or more) in the unselected early human embryonic population (Matsunaga and Shiota, 1977). This estimation may be lower than the actual prevalence as milder forms of HPE also exist but are more difficult to diagnose (Yamada et al., 2004, Yamada, 2006). Well-preserved samples were stored and some of them were selected to be sectioned serially; a total of 500 normal embryos and 500 abnormal embryos were stored as complete serial sections, including HPE embryos.

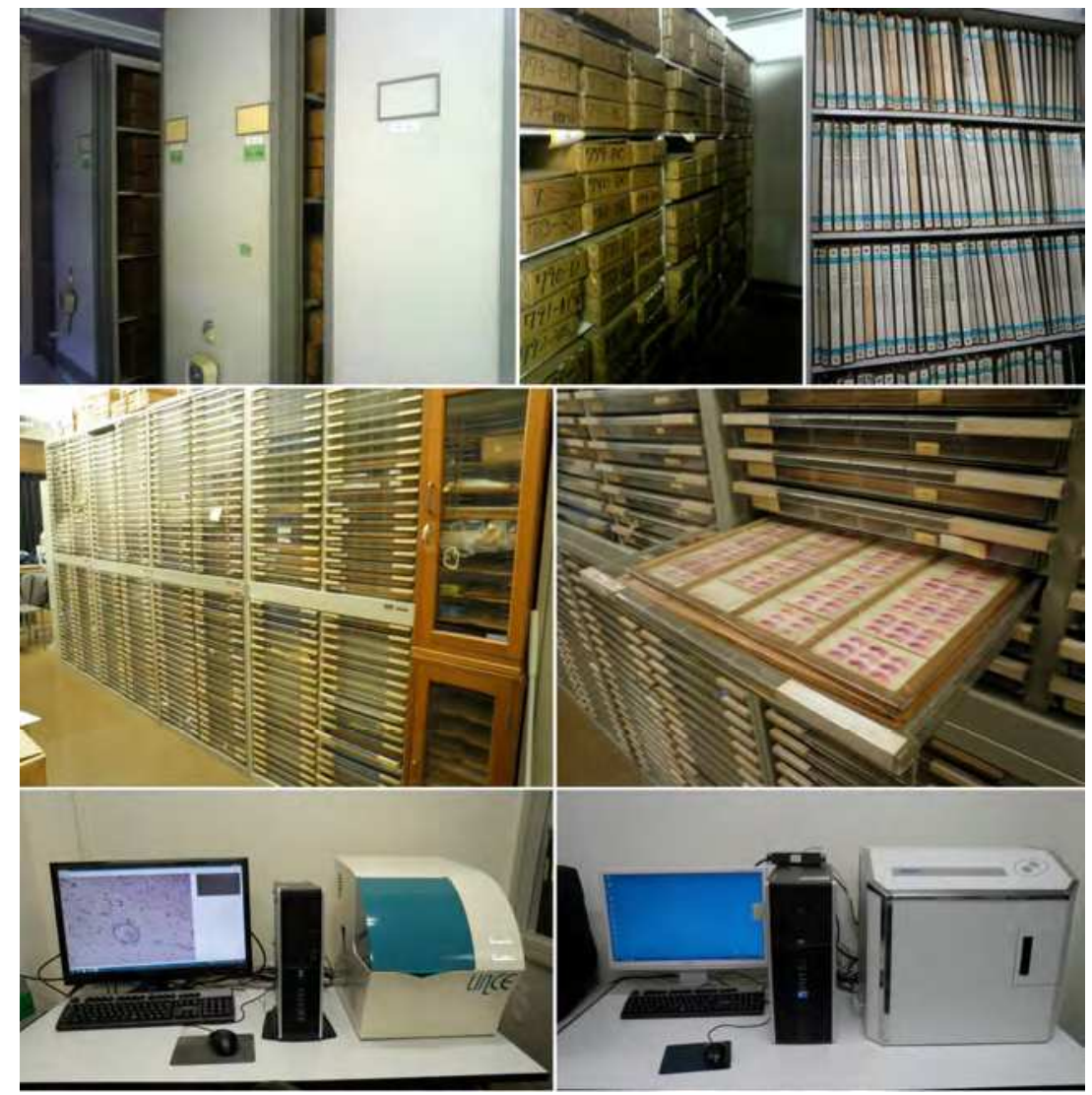

Fig. 2. The Kyoto Collection of Human Embryos. Stock room (top left, top middle), and individual files containing epidemiological data (top right). Histological specimens (middle left, middle right). Digital slide scanners manufactured by Claro Inc. (http:/ / www.claroinc.com/); LINCE (bottom left) and TOCO (bottom right). 
A unique feature of the Kyoto Collection is that maternal epidemiological data and detailed clinical information on the pregnancies were collected in association with every specimen. Based on these epidemiological data, statistical analyses are currently conducted to determine the existence of potential causative links between maternal factors and congenital anomalies (Kameda et al., 2012).

Recently, owing to advances in imaging technologies, embryos can be scanned and 3D digital models can be generated. Using magnetic resonance (MR) microscopes equipped with superconducting magnets ranging from 1.0T to 7.0T, embryos from the Kyoto Collections were imaged (Haishi et al., 2001, Matsuda et al., 2007, Matsuda et al., 2003, Yamada et al., 2010) and morphologically analyzed using 3D reconstruction (Hirose et al., 2011). Episcopic Fluorescence Image Capture (EFIC) and phase-contrast $x$-ray computed tomography have also been applied to human embryos of the Kyoto Collection (Yamada et al., 2010, Yoneyama et al., 2011). Further details on imaging techniques and reconstruction can be found in Chapter 7. Additionally, a project aiming at digitizing all histological sections comprised in the library is now ongoing. As mentioned earlier, the Kyoto Collection contains a register of 1,000 embryos sectioned serially; half of them are classified as normal and the other half with anomalies. The project is currently focusing on serial sections of normal embryos. Parts of the digitized serial sections are accessible from our website (http://atlas.cac.med.kyoto-u.ac.jp).

\section{Human embryonic development}

\subsection{Developmental overview (Carnegie stages: CS)}

Classification into developmental stages is necessary to accurately describe prenatal growth. Embryonic staging of animals was introduced at the end of the 19th century (Hopwood, 2007), and was first applied to human embryology by Mall (1914), as described earlier. At first, human embryos were classified based on their length on the basis of "3-mm stage", but the approach was quickly abandoned due to high inter-individual variations. Subsequently, Streeter $(1942,1945,1948,1951)$ developed a 23-stage developmental scheme of human embryos, commonly known as the Carnegie stages, a staging scheme which remains widely used today. Here below are illustrated all 23 stages using computer graphics either based on photographs acquired in multiple directions, with precise measurements (CS 1-12), or based on data acquired by magnetic resonance microscopy (Yamada et al., 2006, Matsuda et al., 2003).

\section{Relation between the Carnegie stage and estimated age after fertilization (Table 1)}

It is accepted that a wide range of normal variations can occur in actual human embryonic age for any given Carnegie stage. The standard criteria proposed by O'Rahilly and Müller (1987) are close to those suggested by Olivier and Pineau (1962). It is also important to point out that Streeter's human series included pathological specimens obtained from spontaneous abortion or ectopic implantation. In the present chapter, the CG models ranging from CS1 to CS11 were based on Carnegie criteria (O'Rahilly and Müller, 1987), while CS13 to CS23 were based on Kyoto Collection samples (Nishimura et al., 1968, Nishimura et al., 1974). 


\begin{tabular}{c|cccccc}
\hline \multirow{2}{*}{$\begin{array}{c}\text { Carnegie } \\
\text { stage } \\
(\text { CS })\end{array}$} & $\begin{array}{c}\text { Streeter (1942, } \\
\text { 1945, 1948, } \\
1951)\end{array}$ & $\begin{array}{c}\text { Nishimura } \\
(1968,1974)\end{array}$ & $\begin{array}{c}\text { Olivier and } \\
\text { Pineau } \\
(1962)\end{array}$ & $\begin{array}{c}\text { Iffy et al. } \\
(1967)\end{array}$ & $\begin{array}{c}\text { Jirásek } \\
(1971)\end{array}$ & $\begin{array}{c}\text { O'Rahilly and } \\
\text { Müller (1987) }\end{array}$ \\
\hline 11 & 24 & 27 & 24 & - & $23-26$ & $23-25$ \\
12 & 26 & 30 & 26 & - & $26-30$ & $25-27$ \\
13 & 28 & 32 & 28 & 28 & $28-32$ & 28 \\
14 & 29 & $34-35$ & 32 & 32 & $31-35$ & 32 \\
15 & 31.5 & 36 & 33 & 34.5 & $35-38$ & 33 \\
16 & 33 & 38 & 37 & 37 & $37-42$ & 37 \\
17 & 35 & 40 & 41 & 40 & $42-44$ & 41 \\
18 & 37 & 42 & 44 & 43 & $44-48$ & 44 \\
19 & 39 & 44 & 47.5 & 45 & $48-51$ & $47-48$ \\
20 & 41 & 46 & 50.5 & 47 & $51-53$ & $50-51$ \\
21 & 43 & 48 & 52 & 48.5 & $53-54$ & 52 \\
22 & 45 & 50 & 54 & 50 & $54-56$ & 54 \\
23 & 47 & 52 & 56.5 & 52 & $56-60$ & $56-57$ \\
\hline
\end{tabular}

Table 1. Estimated ovulation age (days) based on developmental stages (CS) of human embryos, according to various authors. Modified from Nishimura (1983).

\section{Carnegie stage 1: Fertilized ovum}

\section{1 day after fertilization, $0.1 \mathrm{~mm}$ in diameter}

The oocyte is $120-150 \mu \mathrm{m}$ in diameter and is surrounded by the zona pellucida. The second maturation division of the oocyte completes as the sperm penetrates the egg (fertilization). The sperm head and the nucleus of the oocyte then swell to form the male and female pronuclei, respectively. Once they unite, the resultant diploid cell is called the zygote. The first mitotic division soon begins.

\section{Carnegie stage 2: Cleavage}

\section{5-3 days after fertilization, $0.1-0.2 \mathrm{~mm}$ in diameter}

The conceptus is composed of two to 16 cells but has no blastocystic cavity yet and the zona pellucida can still be easily recognized. The size of the embryo is $0.1-0.2 \mathrm{~mm}$ in diameter. The cell division at this stage is called cleavage since furrows (clefts) appear as the cytoplasm divides. The daughter cells are called blastomeres. An embryo with 16-32 cells is called a morula.

\section{Carnegie stage 3: Free blastocyst}

\section{4 days after fertilization, $0.1-0.2 \mathrm{~mm}$ in diameter}

The conceptus is a free (unattached) blastocyst. The blastocyst is a hollow mass of cells characterized by the blastocystic cavity. The blastocystic cavity begins by the coalescence of intercellular spaces when the embryo has acquired about 32 cells. The blastomeres segregate into an internally situated inner cell mass and an outer trophoblast. The trophoblast cells form an epithelial arrangement with tight junctions. 


\section{Carnegie stage 4: Attaching blastocyst}

5-6 days after fertilization, 0.1-0.2 $\mathrm{mm}$ in diameter

This stage is characterized by the attached blastocyst, which corresponds to the onset of implantation. Attachment of the embryo occurs only once the endometrium has entered the secretory phase. At the site of attachment, the trophoblast cells are transformed into a

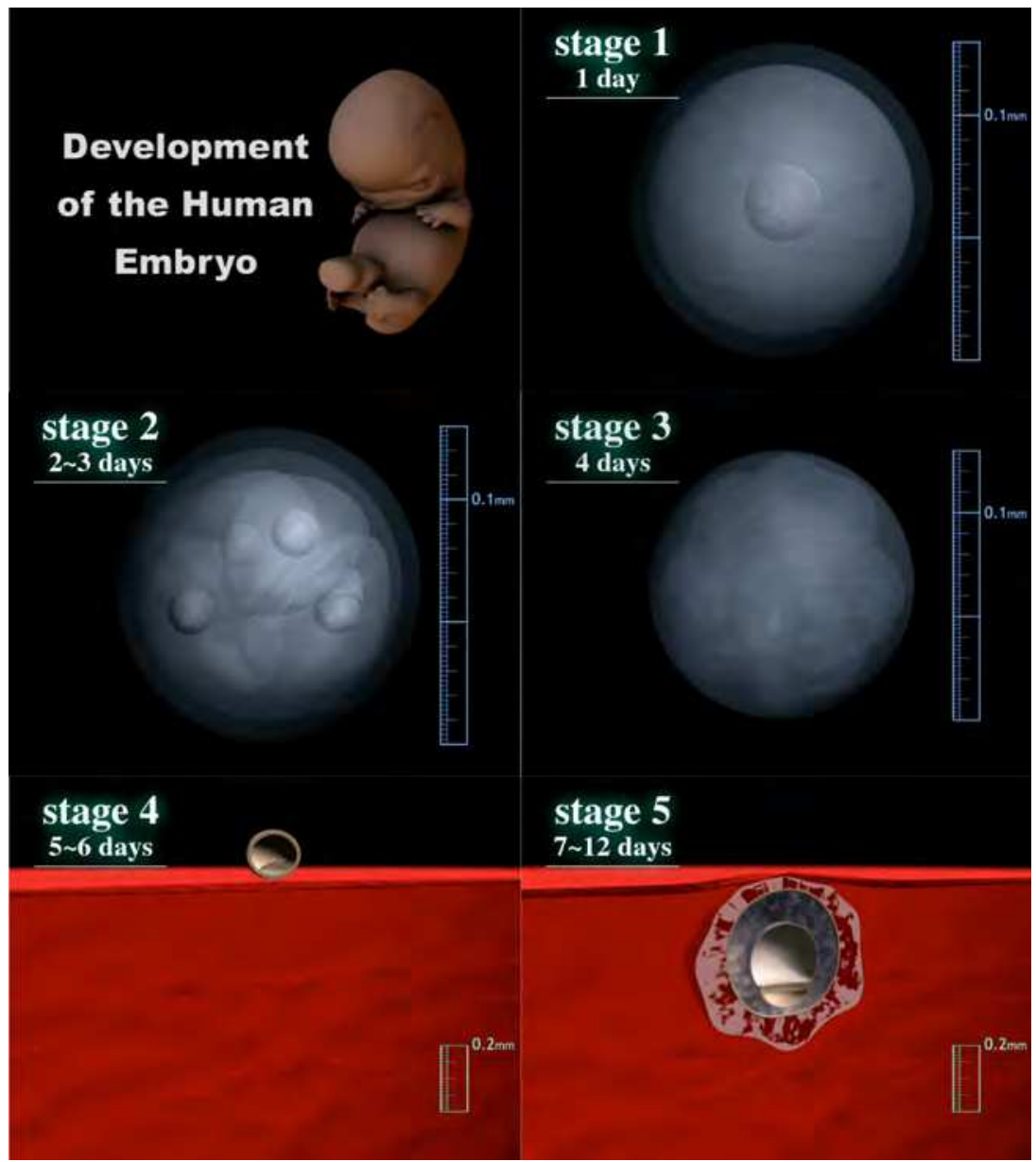

Fig. 3. Computer graphics illustrating embryonic human development: Carnegie stage 1-5. syncytium and penetrate into the endometrial epithelium.

\section{Carnegie stage 4: Attaching blastocyst}

5-6 days after fertilization, 0.1-0.2 $\mathrm{mm}$ in diameter

This stage is characterized by the attached blastocyst, which corresponds to the onset of implantation. Attachment of the embryo occurs only once the endometrium has entered the secretory phase. At the site of attachment, the trophoblast cells are transformed into a syncytium and penetrate into the endometrial epithelium. 
Carnegie stage 5: Implanted but previllous

7-12 days after fertilization, 0.1-0.2 $\mathrm{mm}$ in diameter

The blastocyst penetrates into the endometrium. The trophoblast grows rapidly but is previllous, i.e., it does not yet show definite chorionic villi. This stage is sub-divided into 3 stages according to the differentiation status of the trophoblast: solid trophoblast (stage 5a), lacunar trophoblast (5b), and perfusion of lacunae with maternal blood (5c).

Carnegie stage 6: Chorionic villi and primitive streak 13 days after fertilization, $0.2 \mathrm{~mm}$ in size

Chorionic villi appear and begin to branch. Trophoblastic lacunae coalesce to form the intervillous space (6a). The extra-embryonic mesoderm arises and the chorionic cavity is formed. The yolk sac is now called the secondary (definitive) yolk sac. The primitive streak appears later during this stage (6b, "stage 6" in Fig. 2).

Carnegie stage 7: Notochordal process

16 days after fertilization, $0.4 \mathrm{~mm}$ in length (embryonic disc)

The notochordal process develops in the mesodermal layer rostral to the primitive node. The length of the notochordal process varies from 0.03 to about $0.3 \mathrm{~mm}$. The embryonic mesoderm spreads laterally and rostrally from the primitive streak. The embryonic disc grows cranially and the amniotic cavity expands over the yolk sac.

Carnegie stage 8 : Primitive pit, neuenteric canal 18 days after fertilization, $1.0 \mathrm{~mm}$ in CRL (crown-rump length)

This stage is characterized by the formation of the primitive pit, the notochordal canal and the neurenteric canal. Somites are not yet visible (presomitic stage). The embryonic disc is pyriform, tapering caudally. The notochordal canal is marked by the cavity extending from the primitive pit into the notochordal process. The floor of the canal soon disappears to form a passage between the amniotic cavity and the yolk sac (neurenteric canal).

Carnegie stage 9: 1-3 pairs of somites

20 days after fertilization, $1.5 \mathrm{~mm}$ in CRL

The neural groove and the first somites appear, and one to three pairs of somites can be observed. The embryonic disc resembles a shoe-sole, with the broad neural plate positioned into the cranial region. The neural groove appears during this stage and subsequently deepens. The paraxial mesoderm becomes segmented to form somites.

Carnegie stage 10: Neural folds begin to fuse, 4-12 pairs of somites 22 days after fertilization, $1.8 \mathrm{~mm}$ in CRL

The neural groove deepens and the neural folds begin to fuse to form the neural tube. The fusion of neural folds extends bidirectionally. The optic sulcus and branchial arch 1 (i.e., pharyngeal arch) begin to be visible. The cardiac loop starts to appear.

\section{Carnegie stage 11: Anterior neuropore closes}

24 days after fertilization, $2.5-3 \mathrm{~mm}$ in CRL

The human embryo now has 13-20 pairs of somites. The anterior neuropore is now closing up. Optic evagination is produced at the optic sulcus and the optic ventricle is continuous with that of the forebrain. The sinus venosus develops in the cardiac loop. The 


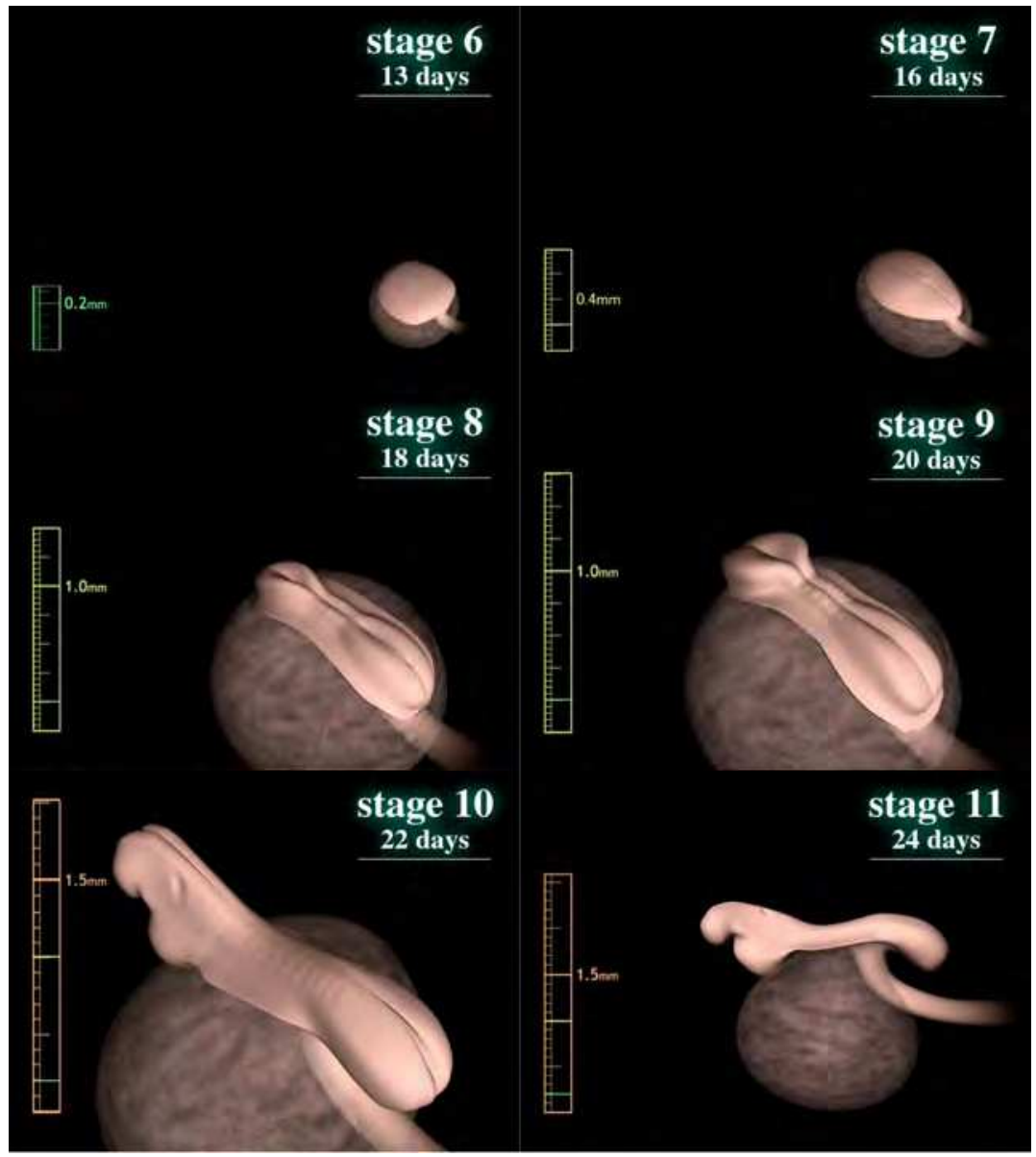

Fig. 4. Computer graphics illustrating human embryonic development: Carnegie stage 6-11. (buccopharyngeal) membrane is ruptured. The otic vesicle is now formed.

Carnegie stage 12: Posterior (caudal) neuropore closes, 3-4 branchial arches, upper limb buds 28 days after fertilization, $4 \mathrm{~mm}$ in CRL

The posterior (caudal) neuropore is starting to close or is closed. Three branchial arches are present. Upper limb buds are distinct. The embryo now has 21-29 pairs of somites. The embryonic axis is curved as a result of the rounding out or the folding of the embryo. Internally, the lung bud appears and the interventricular septum has begun its formation in the heart.

\section{Carnegie stage 13: Four limb buds, optic vesicle} 32 days after fertilization, $5 \mathrm{~mm}$ in CRL

Two upper and two lower limb buds are visible. The optic vesicle can be easily recognized and the lens placode begins to differentiate. The embryo now has more than 30 pairs of 
somites, but the number of somites becomes increasingly difficult to determine and is no longer used in staging.

\section{Carnegie stage 14: Lens pit and optic cup} 34 days after fertilization, $6 \mathrm{~mm}$ in CRL

The lens pit invaginates into the optic cup but is not yet closed. The endolymphatic appendage emerging from the otic vesicle is well defined. The upper limb buds elongate and become tapering. The cephalic and cervical flexures are prominent. Internally, the future cerebral hemispheres and cerebellar plates are visible. The dorsal and ventral pancreatic buds are noticeable. The ureteric bud develops and acquires a metanephrogenic blastemal cap.

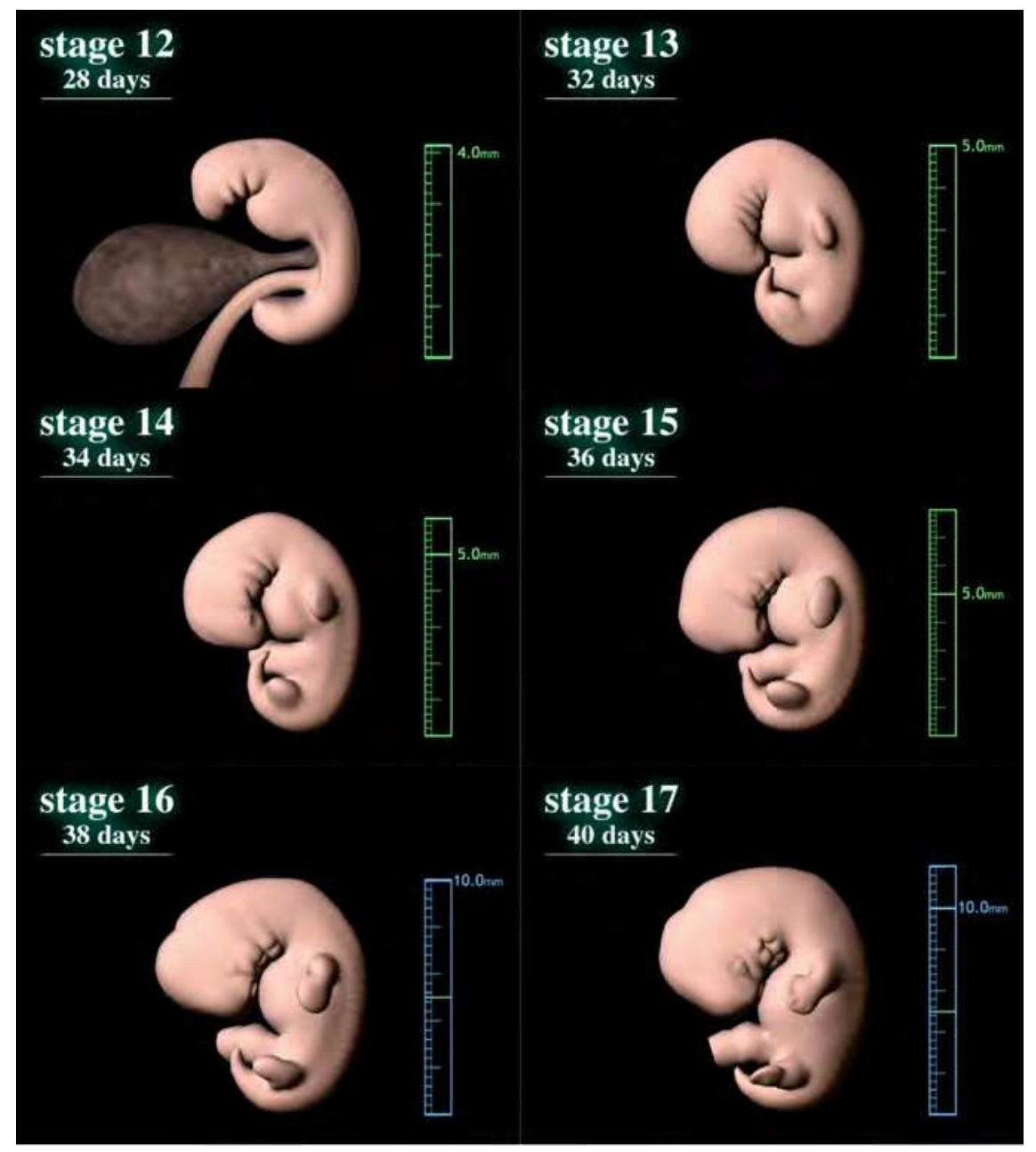

Fig. 5. Computer graphics illustrating human embryonic development: Carnegie stage 12-17. 
Carnegie stage 15: Lens vesicles, nasal pit and hand plates 34 days after fertilization, $8 \mathrm{~mm}$ in CRL

Lens vesicles are closed and covered by the surface ectoderm. The nasal plate invaginates to form a nasal pit. Auricular hillocks arise. Hand plates are forming. The foramen secundum develops in the heart. Lung buds begin to branch into lobar buds. The primary urogenital sinus is formed.

\section{Carnegie stage 16: Nasal pit faces ventrally, retinal pigment, foot plate} 38 days after fertilization, $10 \mathrm{~mm}$ in CRL

Nasal pits deepen and come to face ventrally. Retinal pigment is visible externally. The hand plates are now distinct and the foot plate is emerging. The nasolacrimal groove has formed between the frontal and maxillary processes.

Carnegie stage 17: Head relatively larger, nasofrontal groove, finger rays 40 days after fertilization, $11 \mathrm{~mm}$ in CRL

The head is relatively larger than previously and the trunk has become straighter. The auricular hillocks and nasofrontal (nasolacrimal) grooves are distinct. The hand plates exhibit definite digital rays, and the foot has acquired a rounded digital plate.

Carnegie stage 18: Elbows, toe rays, eyelid folds, nipples 42 days after fertilization, $13 \mathrm{~mm}$ in CRL

The body shape is more cuboidal. Both cervical and lumbar flexures are denoted. The elbows are discernible and interdigital notches appear in the hand plates. Toe rays are observed in the foot plate. Eyelid folds appear. Auricular hillocks are being transformed into specific parts of the external ear. Ossification may begin in some skeletal structures.

\section{Carnegie stage 19: Trunk elongation and straightening} 44 days after fertilization, $16 \mathrm{~mm}$ in CRL

The trunk begins to elongate and straightens. Eyes and external ears gain definite shape. The eyes are positioned in the front of the face, owing to the growth of the brain. The upper and lower limbs are almost parallel, with pre-axial borders cranially and postaxial borders caudally. Intestines have developed and parts of them can be observed in normal umbilical cord (physiological umbilical hernia).

\section{Carnegie stage 20: Longer upper limb bent at elbow} 46 days after fertilization, cranio-rump length: $19 \mathrm{~mm}$ in CRL

The angle of cervical flexure becomes small, and the direction of the head goes up. Vascular plexus appears in the superficial tissues of the head. The coiled intestine observed in the umbilical cord has developed. Spontaneous movement begins at this stage. The upper limbs have increased in length and become bent at the elbows and hand joints. Fingers are curving slightly over the chest.

\section{Carnegie stage 21: Fingers longer, hands approach each other} 48 days after fertilization, cranio-rump length: $21 \mathrm{~mm}$ in CRL

The head becomes round. The superficial vascular plexus of the head has spread and surrounds the head. The tail becomes rudimentary. The hands are slightly flexed at the wrists and nearly come together over the cardiac prominence. 
Carnegie stage 22: Eyelids and external ear more developed 50 days after fertilization, $23 \mathrm{~mm}$ in CRL

The vascular plexus of the head becomes distinct. The eyelids are thickening and encroaching into the eyes. The tragus and antitragus of the external ear are assuming a more definite form. The position of the external ears becomes higher on the head. The tail has almost disappeared.

\section{Carnegie stage 23: End of embryonic period} 52 days after fertilization, $30 \mathrm{~mm}$ in CRL

The head has rounded out and the trunk has adopted a more mature shape. The eyelids and ear auricles become definite. The limbs have increased in length and the forearm ascends to or above the level of the shoulder. The vascular plexus is approaching the vertex of the head. The tail has now disappeared. The external genitalia are relatively well developed but sex difference is not yet obvious externally.

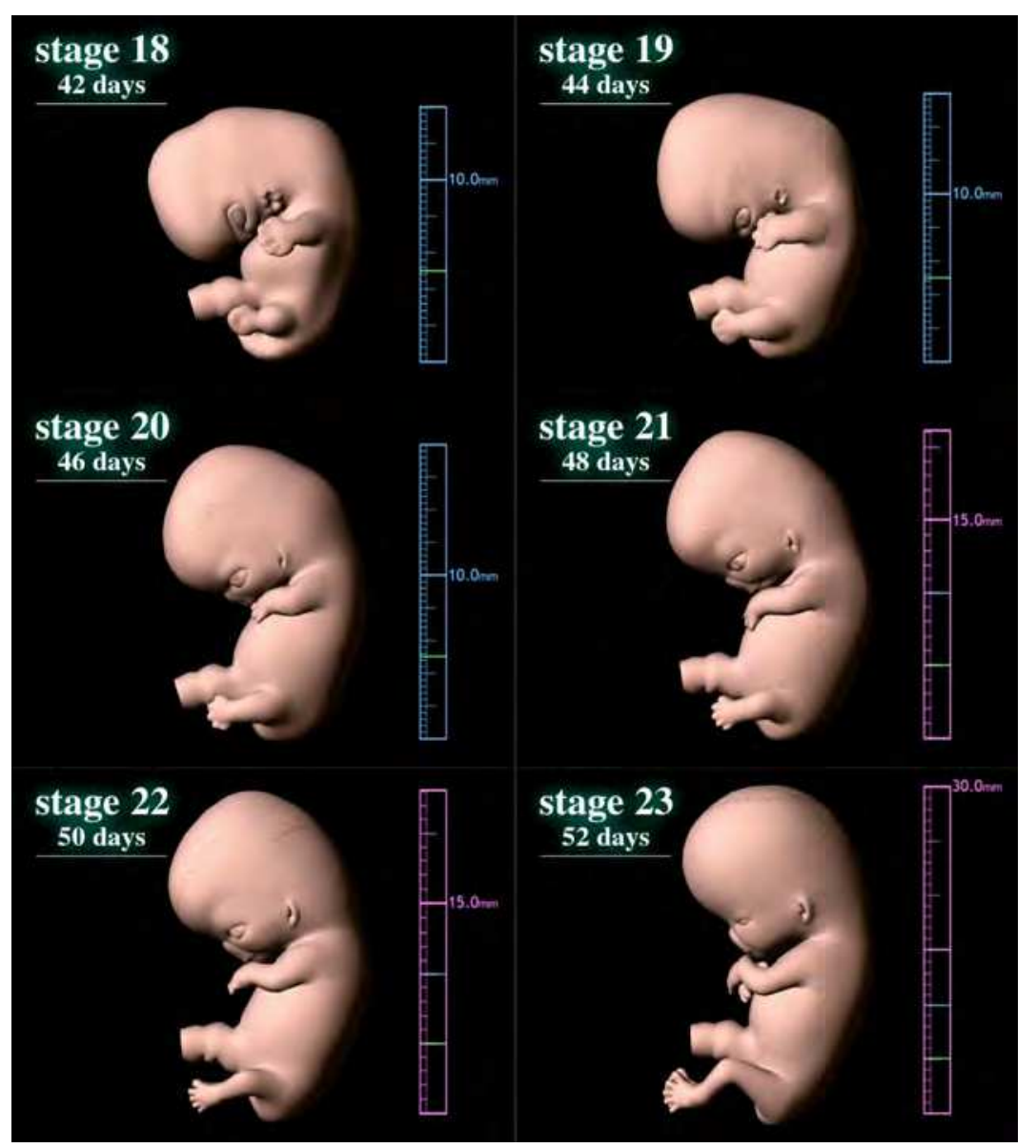

Fig. 6. Computer graphics illustrating human embryonic development: Carnegie stage 18-23. 


\subsection{The face}

Three pharyngeal arches appear at Carnegie stage 12. The 1st pharyngeal gives rise to the maxillary and mandibular prominences (stage 13, Fig. 8), which will then constitute the lateral and caudal boundaries of the stomodeum (i.e., primitive oral cavity), respectively.
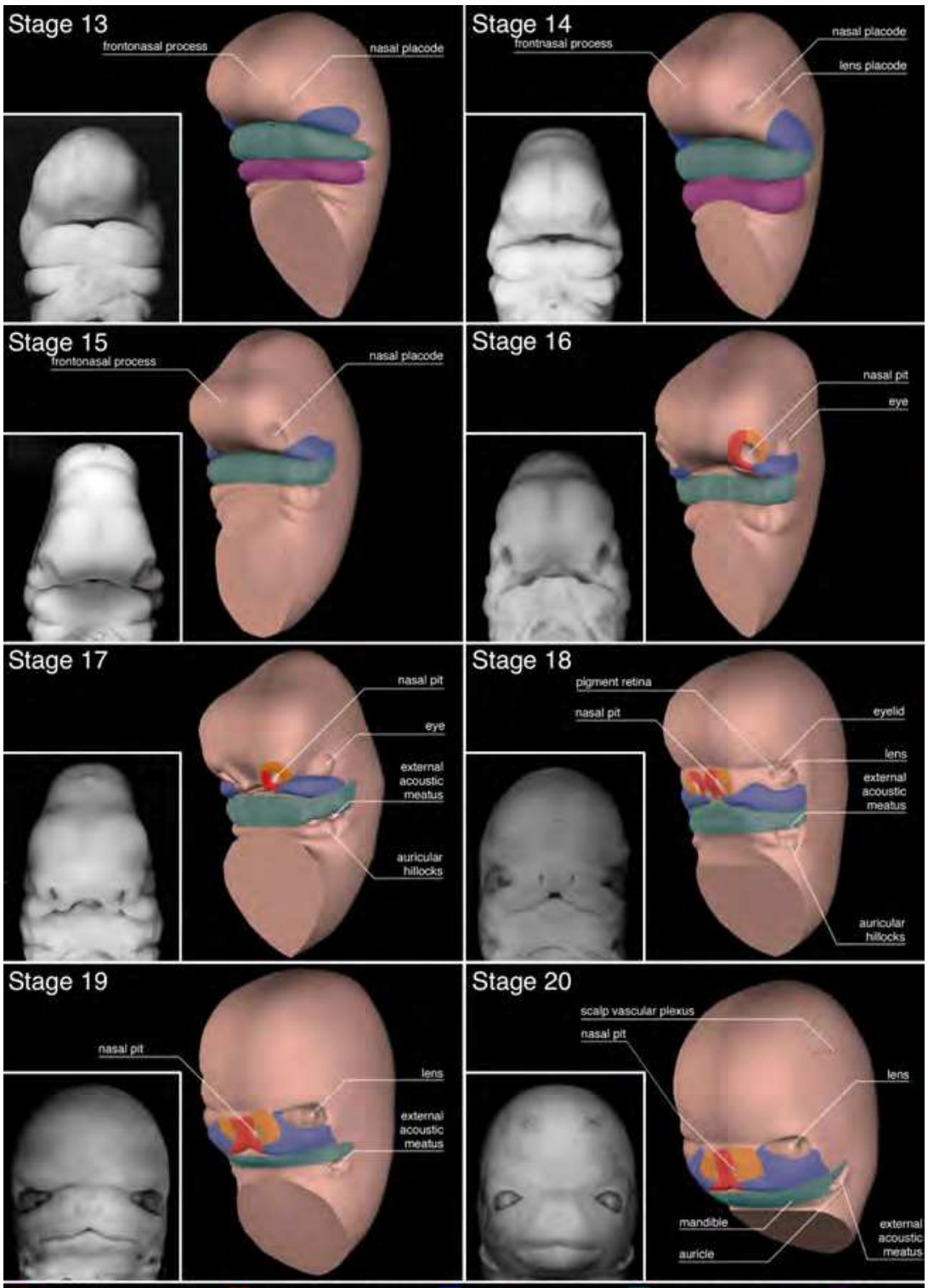

medial nasal prominence

lateral nasal prominence

maxillary prominence

mandibular prominence

hyoid arch

Fig. 7. Embryonic development of the face (stages 13-20). 
The side and front of the neck arise from the 2nd pharyngeal arch, also known as the hyoid arch. The frontonasal prominence (FNP) grows to cover the ventral part of the forebrain (stage 13). It will form the forehead (frontal part of the FNP) and the primordial mouth and nose (nasal part of the FNP).

By the end of the 4th developmental week, nasal placodes (thickening of surface ectoderm to become peripheral neural tissue) develop on the frontolateral aspects of the FNP (stage 13). The mesenchyme swells around the nasal placodes resulting in medial and lateral nasal prominences (stage 16). The maxillary prominence will merge with the medial nasal prominences, and cause their fusion. The fused medial nasal prominences will form the midline of the nose and that of the upper lip, as well as the primary palate (stage 16-18). The nasolacrimal groove divides the lateral nasal prominence from the maxillary prominence (observed in stages 16,17).

The 5th developmental week sees the formation of the primordial ear auricles around the first pharyngeal groove, at the interface between the mandibular prominences and the hyoid arches (stage 16). The auricular hillocks give rise to the auricle while the external acoustic meatus arises from the first pharyngeal groove. At the early period of ear development, the external ears are located in the neck region, and they ascend to the side of the head at the level of the eyes as the development of the mandible (compare Fig. 8 with stage 23 in Fig. 6).

The maxillary and lateral nasal prominences will fuse with the nasolacrimal groove during the 6th developmental week, and result in continuity between the nose and cheek ( stage 18).

The 7th developmental week is marked by the fusion of the two medial nasal prominences with the maxillary and lateral nasal prominences (stage 19 ). The merge between the maxillary and medial nasal prominences creates continuity between the upper jaw and lip, and results in partition of the nasal cavity from the oral cavity.

\subsection{Upper and lower extremities}

The embryonic development of the limbs (O'Rahilly and Gardner, 1975) is illustrated here using computer graphics (Yamada et al., 2006).

\section{Carnegie stage 12}

The upper limb buds start to develop.

\section{Carnegie stage 13}

The upper limb buds appear in a definite manner, and the lower limb buds start to develop.

\section{Carnegie stage 14}

The upper limb buds grow and taper toward the tip, which will later form the hand plate. Innervation and blood supply begin at CS14 in the upper limbs. The development of the lower limb buds is delayed in respect to the upper limb buds.

\section{Carnegie stage 15}

The hand plates are distinct in the upper limb buds. In the lower limbs, the rostral half is rounded but the caudal half is tapered. Innervation begins in the lower limb buds. 


\section{Carnegie stage 16}

Hand plates form a central, carpal part and a digital flange. Lower limb buds form a femoral part, a crural part and foot plate.

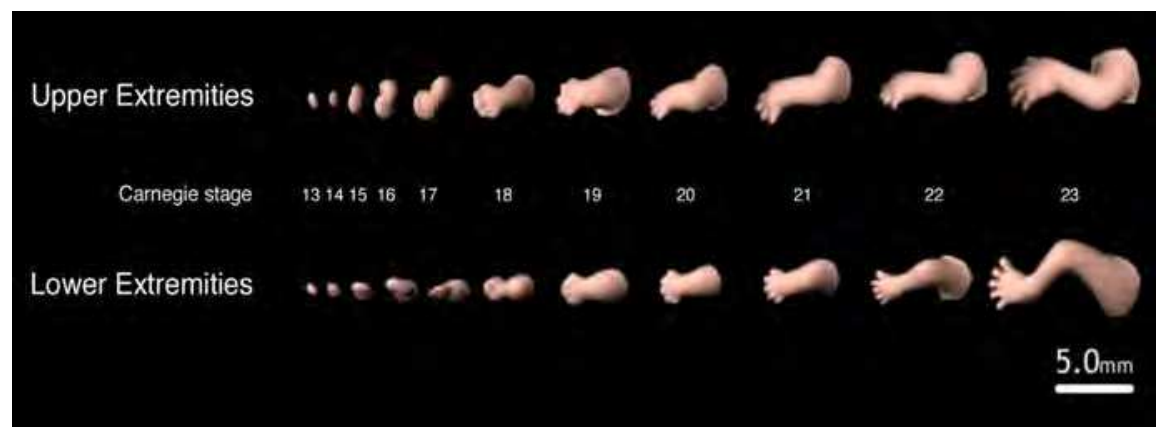

Fig. 8. Embryonic development of upper and lower limbs (CS13-CS23).

\section{Carnegie stage 17}

Finger rays appear in the hand plate, and the rim of the hand plate is crenated due to the presence of individual fingers in some advanced specimens. The lower limb buds have increased in size and a rounded digital plate is set off from the crurotarsal region.

\section{Carnegie stage 18}

The upper limbs have increased in length and become slightly bent at the elbow. Finger rays are distinct. Toe rays appear but the rim of the foot plate is not yet definitely notched in the lower limb bud.

\section{Carnegie stage 19}

The upper limbs rotate medially and seem to hold the chest. Apoptosis occurs in the mesenchymal tissues of interdigital areas, and creates deeper interdigital notches. Toe rays are prominent and interdigital notches appear in the foot plate. Knees and ankles start to appear.

\section{Carnegie stage 20}

The upper limbs are bent at the elbow and hand joints, resulting in a pronated position. The lower limbs are also bent at the knee joints. Notches are present between the toe rays in the foot plate.

\section{Carnegie stage 21}

Elbows in the upper limbs and knees in the lower limbs now become distinct. Hands cross each other in front of the chest. Fingers are longer and distal phalangeal portions are slightly swollen, indicating the beginning of palmar pads. The feet are also approaching each other.

\section{Carnegie stage 22}

Hands extend in front of the body and the fingers of one hand may overlap those of the other. Feet approach each other, but toe digits are still webbed. 


\section{Carnegie stage 23}

Upper and lower limbs are well formed. They have lengthened and are bent at joints. Fingers get longer and toes are no longer webbed, all digits are now separate and distinct.

\section{Conclusion}

Large-scale human embryo collections started in the early $20^{\text {th }}$ century and contributed to tremendous progress in human embryology. These compendiums of embryonic specimens are still widely used today, and are exploited through modern technologies such as imaging techniques and computer sciences. Using computer graphics prepared from specimens housed at the Kyoto Collection of Human Embryos, here we provided a clear overview of human embryonic development, with a special emphasis on the limbs and the face.

\section{Acknowledgments}

We are deeply grateful to Ms. Elizabeth Lockett at the National Museum of Health and Medicine, Washington D.C., for providing information on the Carnegie Collection; Dr. Sumiko Kimura for assistance and guidance in the experiments; Ms. Chigako Uwabe at the Congenital Anomaly Research Center at Kyoto University Graduate School of Medicine for technical assistance; Prof. Michihiko Minoh, Dr. Takuya Funatomi, Dr. Tamaki Motoki, Ms. Mikiko Takahashi, and Mr. Yutaka Minekura at the Academic Center for Computing and Media Studies at Kyoto University, for generating the computer graphics of human embryos; and Prof. Kohei Shiota, Vice President of Kyoto University for his support and guidance on the project. Part of this research was financially supported by Grants \#228073, \#238058, \#21790180 and \#22591199 from the Japan Society for the Promotion of Science (JSPS) and the Japan Science and Technology (JST) institute for Bioinformatics Research and Development (BIRD). The studies presented in this chapter were approved by the Medical Ethics Committee at Kyoto University Graduate School of Medicine (Kyoto, Japan).

\section{References}

Brown, D. D. 1987. The Department of Embryology of the Carnegie Institution of Washington. BioEssays : news and reviews in molecular, cellular and developmental biology, 6, 92-6.

Haishi, T., Uematsu, T., Matsuda, Y. \& Kose, K. 2001. Development of a 1.0 T MR microscope using a Nd-Fe-B permanent magnet. Magnetic resonance imaging. 19, 875-80.

Hirose, A., Nakashima, T., Yamada, S., Uwabe, C., Kose, K. \& Takakuwa, T. 2012. Embryonic liver morphology and morphometry by magnetic resonance microscopic imaging. Anatomical record: advances in integrative anatomy and evolutionary biology. 2011. 295, 51-59.

Hopwood, N. 2007. A history of normal plates, tables and stages in vertebrate embryology. The International journal of developmental biology, 51, 1-26.

Iffy, L., Shepard, T. H., Jakobovits, A., Lemire, R. J. \& Kerner, P. 1967. The rate of growth in young human embryos of Streeter's horizons. 13 to 23. Acta anatomica, 66, 178-86. 
Jirásek, J. E. 1971. Development of the genital system and male pseudohermaphroditism, Baltimore, Johns Hopkins Press.

Kameda, T., Yamada, S., Uwabe, C., Shiota, K. \& Suganuma, N. 2012. Digitization of clinical and epidemiological data from the Kyoto Collection of Human Embryos: maternal risk factors and embryonic malformations. Congenital Anomalies. doi: 10.1111/j.1741-4520.2011.00349.x

Mall, F. P. 1914. On stages in the development of human embryos from 2 to $25 \mathrm{~mm}$ long. ANATOMISCHER ANZEIGER, 46, 78-84.

Matsuda, Y., Ono, S., Otake, Y., Handa, S., Kose, K., Haishi, T., Yamada, S., Uwabe, C. \& Shiota, K. 2007. Imaging of a large collection of human embryo using a superparallel MR microscope. Magnetic resonance in medical sciences: MRMS: an official journal of Japan Society of Magnetic Resonance in Medicine. 6, 139-46.

Matsuda, Y., Utsuzawa, S., Kurimoto, T., Haishi, T., Yamazaki, Y., Kose, K., Anno, I. \& Marutani, M. 2003. Super-parallel MR microscope. Magnetic resonance in medicine : official journal of the Society of Magnetic Resonance in Medicine / Society of Magnetic Resonance in Medicine. 50, 183-9.

Matsunaga, E. \& Shiota, K. 1977. Holoprosencephaly in human embryos: epidemiologic studies of 150 cases. Teratology, 16, 261-72.

Nishimura, H. 1974. Detection of early developmental anomalies in human abortuses. In: Gianantonio, C. A., Berri, G. G. (ed.) Pediatria XIV. Buenos Aires: Editorial Medica Panamericana.

Nishimura, H. 1975. Prenatal versus postnatal malformations based on the Japanese experience on induced abortions in the human being. . In: BLANDEU, R. (ed.) Aging Gamates. Basel: S. Karger AG.

Nishimura, H. 1983. Introduction. In: Nishimura, H. (ed.) Atlas of Human Prenatal Histology. Tokyo: Igaku-shoin.

Nishimura, H., Takano, K., Tanimura, T. \& Yasuda, M. 1968. Normal and abnormal development of human embryos: first report of the analysis of 1,213 intact embryos. Teratology, 1, 281-90.

Nishimura, H., Tanimura, T., Semba, R. \& Uwabe, C. 1974. Normal development of early human embryos: observation of 90 specimens at Carnegie stages 7 to 13. Teratology, $10,1-5$.

O'Rahilly, R. 1988. One Hundred Years of Human Embryology. In: KALTER, H. (ed.) Issues and Reviews in Terratology New York: Plenum Press.

O'Rahilly, R. \& Gardner, E. 1975. The timing and sequence of events in the development of the limbs in the human embryo. Anatomy and embryology. 148, 1-23.

O'Rahilly, R. \& Müller, F. 1987. Developmental stages in human embryos: including a revision of Streeter's "horizons" and a survey of the Carnegie Collection., Washington, DC, Carnegie Institution of Washington Publication.

Olivier, G. \& Pineau, H. 1962. Horizons de Streeter et age embryonnaire. Bulletin de l'Association des anatomistes. 47, 573-576.

Shiota, K. 1991. Development and intrauterine fate of normal and abnormal human conceptuses. Congenit Anom Kyoto, 31, 67-80.

Streeter, G. L. 1942. Developmental horizons in human embryos. Description of age group XI, 13 to 20 somites, and age group XII, 21 to 29 somites. Carnegie Institution of Washington publication 541, Contributions to Embryology, 30, 211-245. 
Streeter, G. L. 1945. Developmental horizons in human embryos. Description of age group XIII, embryos about 4 or 5 millimeters long, abd age group XIV, period of indentation of the lens vesicle. Carnegie Institution of Washington publication 557, Contributions to Embryology, 31, 27-63.

Streeter, G. L. 1948. Developmental horizons in human embryos. Description of age groups XV, XVI, XVII, and XVIII, being the third issue of a survey of the Carnegie Collection. Carnegie Institution of Washington publication 575, Contributions to Embryology, 32, 133-203.

Streeter, G. L. 1951. Developmental horizons in human embryos. Description of age groups XIX, XX, XXI, XXII, and XXIII, being the fifth issue of a survey of the Carnegie Collection (prepared for publication by C. H. Heuser and G. W. Corner). Carnegie Institution of Washington publication 592, Contributions to Embryology, 34, 165-196.

Yamada, S. 2006. Embryonic holoprosencephaly: pathology and phenotypic variability. Congenital anomalies, 46, 164-71.

Yamada, S., Samtani, R. R., Lee, E. S., Lockett, E., Uwabe, C., Shiota, K., Anderson, S. A. \& Lo, C. W. 2010. Developmental atlas of the early first trimester human embryo. Developmental dynamics : an official publication of the American Association of Anatomists, 239, 1585-95.

Yamada, S., Uwabe, C., Fujii, S. \& Shiota, K. 2004. Phenotypic variability in human embryonic holoprosencephaly in the Kyoto Collection. Birth defects research. Part A, Clinical and molecular teratology. 70, 495-508.

Yamada, S., Uwabe, C., Nakatsu-Komatsu, T., Minekura, Y., Iwakura, M., Motoki, T., Nishimiya, K., Iiyama, M., Kakusho, K., Minoh, M., Mizuta, S., Matsuda, T., Matsuda, Y., Haishi, T., Kose, K., Fujii, S. \& Shiota, K. 2006. Graphic and movie illustrations of human prenatal development and their application to embryological education based on the human embryo specimens in the Kyoto collection. Developmental dynamics : an official publication of the American Association of Anatomists, 235, 468-77.

Yoneyama, A., Yamada, S. \& Takeda, T. 2011. Fine Biomedical Imaging Using X-Ray PhaseSensitive Technique. In: Gargiulo, D. G., Mcewan, A. (ed.) Advanced Biomedical Engineering. InTech. p107-128. 


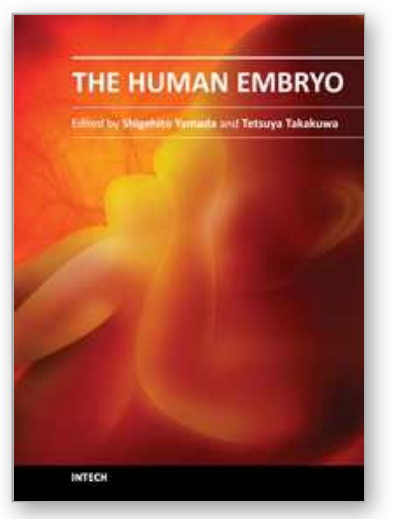

\author{
The Human Embryo \\ Edited by Dr. Shigehito Yamada
}

ISBN 978-953-51-0124-6

Hard cover, 180 pages

Publisher InTech

Published online 02, March, 2012

Published in print edition March, 2012

Human embryology is now rapidly moving to a new phase due to recent innovation and advances of life science including ES and iPS technology. This new era also directs a difficult challenge for scientists in terms of technological and ethical issues for future human embryology. However, human embryology is difficult to research due to ethics involved in the collection of human materials. This book traces the early history and provides knowledge on demonstration of principles from ancient to the most recent embryo studies amidst the unresolved scientific and ethical issues. We hope this book will help the readers to understand human embryo development better.

\title{
How to reference
}

In order to correctly reference this scholarly work, feel free to copy and paste the following:

Shigehito Yamada, and Tetsuya Takakuwa (2012). Introduction - Developmental Overview of the Human Embryo, The Human Embryo, Dr. Shigehito Yamada (Ed.), ISBN: 978-953-51-0124-6, InTech, Available from: http://www.intechopen.com/books/the-human-embryo/introduction-overview-of-development-in-humanembryos

\section{INTECH}

open science | open minds

\section{InTech Europe}

University Campus STeP Ri Slavka Krautzeka 83/A 51000 Rijeka, Croatia

Phone: +385 (51) 770447

Fax: +385 (51) 686166 www.intechopen.com

\section{InTech China}

Unit 405, Office Block, Hotel Equatorial Shanghai No.65, Yan An Road (West), Shanghai, 200040, China 中国上海市延安西路65号上海国际贵都大饭店办公楼 405 单元 Phone: +86-21-62489820

Fax: +86-21-62489821 
(C) 2012 The Author(s). Licensee IntechOpen. This is an open access article distributed under the terms of the Creative Commons Attribution 3.0 License, which permits unrestricted use, distribution, and reproduction in any medium, provided the original work is properly cited. 